https://helda.helsinki.fi

\title{
The effect of relative humidity and formulation variables on chewable xylitol-sorbitol tablets
}

\author{
Juvonen, Henna
}

2021-05-15

Juvonen , H , Antikainen, O , Lemmens , M , Ehlers , H \& Juppo , A 2021 , ' The effect of relative humidity and formulation variables on chewable xylitol-sorbitol tablets ' , International Journal of Pharmaceutics , vol. 601 , 120573 . https://doi.org/10.1016/j.jpharm.2021.120573

http://hdl.handle.net/10138/330553

https://doi.org/10.1016/j.ijpharm.2021.120573

cc_by

publishedVersion

Downloaded from Helda, University of Helsinki institutional repository.

This is an electronic reprint of the original article.

This reprint may differ from the original in pagination and typographic detail.

Please cite the original version. 


\title{
The effect of relative humidity and formulation variables on chewable xylitol-sorbitol tablets
}

\author{
Henna Juvonen $^{\mathrm{a}, \mathrm{b}, *}$, Osmo Antikainen ${ }^{\mathrm{a}}$, Marijke Lemmens ${ }^{\mathrm{a}}$, Henrik Ehlers ${ }^{\mathrm{a}}$, Anne Juppo ${ }^{\mathrm{a}}$

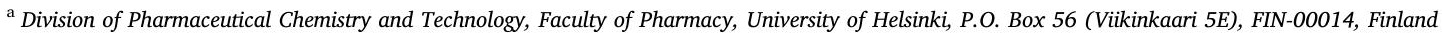 \\ ${ }^{\mathrm{b}}$ Pharmia Oy, Kalliotie 2, FIN-04360, Finland
}

\section{A R T I C L E I N F O}

\section{Keywords:}

Xylitol

Sorbitol

Tablet strength

Sticking

Relative humidity

\begin{abstract}
A B S T R A C T
Changing relative humidity levels challenge the manufacturing of chewable xylitol-sorbitol based tablets. The aim of the study is to investigate how the formulation of chewable xylitol-sorbitol tablets affects the properties of the powder blends and the tablets in an environment of different relative humidity levels. In all, 30 batches containing different ratios of sorbitol, xylitol and magnesium stearate were prepared at three different relative humidity levels. Powder blends were made into tablets using an instrumented eccentric tableting machine. To demonstrate the effect of variables on powder blend and tablet properties, multiple linear regression analysis was performed. It was found that xylitol-sorbitol powder blends and tablets benefitted from the large amount of magnesium stearate, and the high lubricant level negatively affected the quality of the tablets only at high relative humidity. In the presence of high environmental humidity, the amount of sorbitol in the powder mixture must be limited in order to prevent sticking whereas at low relative humidity, higher content of sorbitol is needed to decrease the friability of tablets. Results indicate that alternating relative humidity levels truly challenge the production of xylitol-sorbitol based tablets and if the humidity is not controllable, there is a need for additional filler-binders.
\end{abstract}

\section{Introduction}

Several patient groups, e.g. children and elderly people, may benefit from the chewable tablet dosage form. Tablets have to be easily chewable by the intended patient population and especially organoleptic properties such as mouthfeel, aroma and taste are of importance. The taste issues caused by the active pharmaceutical ingredient should be overcome for the patient compliance. Polyols are used in tablets because of their pleasant sweet taste, low-caloric and non-cariogenic nature. Direct compression grades of polyols are mainly used in tablets for their improved flow and compaction properties (Bolhuis et al., 2009).

Xylitol is reported to deform mainly by fragmenting and sorbitol has a strong plastic deformation ability (Garr and Rubinstein, 1990; Rojas and Hernández, 2014). It has been reported that even commercial grades of xylitol are not always satisfactory for their compaction properties whereas sorbitol is highly compactible (Bolhuis et al., 2009; Garr and Rubinstein, 1990; Mizumoto et al., 2005). Capping of xylitol and sorbitol tablets at high compression forces has been reported (Bolhuis et al., 2009; Morris et al., 1996). Garr and Rubinstein (1990) reported a decrease in xylitol tablet tensile strength after reaching a maximum value with increasing compression force.

Increase in relative humidity affects the flow properties of powders. The hygroscopicity of sorbitol restricts its use (Bolhuis et al., 2009). Hygroscopic and water-soluble compounds such as xylitol and sorbitol adsorb environmental moisture which which may lead to the formation of liquid bridges and thus, increase in the cohesiveness of the powders (Armstrong et al., 2014; Peleg et al., 1973). Moisture can cause caking of the powders which can be detected as flowability reducing aggregates or ultimately, coherent solid mass. As deliquescent materials, xylitol and sorbitol undergo temperature-dependent deliquescence at approx. 80-85 RH\%/25 ${ }^{\circ} \mathrm{C}$ and $65-70 \mathrm{RH} \% / 25{ }^{\circ} \mathrm{C}$, respectively (Bond, 2009; Lipasek et al., 2013; Nezzal et al., 2009; Shur, 2009). Deliquescence of excipients is likely to lead to detrimental physical and chemical instabilities including caking, complete liquefaction of the solid and degradation of incorporated active pharmaceutical ingredients (Mauer and Taylor, 2010). However, moisture sorption isotherm is dependent on raw material quality and properties (Mathlouthi and Rogé, 2003; Stoklosa et al., 2012).

\footnotetext{
* Corresponding author at: Division of Pharmaceutical Chemistry and Technology, Faculty of Pharmacy, University of Helsinki, P.O. Box 56 (Viikinkaari 5E), FIN00014, Finland.

E-mail address: henna.juvonen@iki.fi (H. Juvonen).
} 
Sticking and capping are common problems to polyols, such as xylitol and sorbitol (Bolhuis et al., 2009). Especially hygroscopic materials tend to stick, and sticking propensity increases with increasing humidity. High compression force is reported to prevent sticking because of increase in cohesion within tablet (Saniocki, 2014). On the other hand, high compression force may cause sticking due to increase in true contact area of plastically deforming materials (Abdel-Hamid and Betz, 2012; Waimer et al., 1999). It has been reported that in general, plastically deforming materials tend to have more sticking tendency than brittle materials (Paul et al., 2017). Low melting point has been reported to be one of the potential causes for sticking (Danjo et al., 1993). The relatively low melting points of xylitol and sorbitol are 92-96 ${ }^{\circ} \mathrm{C}$ and $94-96^{\circ} \mathrm{C}$, respectively in the literature (Bond, 2009; Shur, 2009). Magnesium stearate may be used for the prevention of sticking of xylitol and sorbitol because of the anti-adherent effect (Bolhuis et al., 2009; Waimer et al., 1999).

Magnesium stearate is the most commonly used lubricant in tableting. Lubricant film adsorbed on particles reduces the friction between mass and the tableting machine, especially the die wall and punches. It is well known that the thin hydrophobic layer of magnesium stearate on the surface of particles hinders the formation of strong solid bridges between the particles which is seen as a decrease in tablet breaking strength. Bolhuis and Anthony Armstrong (2006) stated that the deformation mechanism is the key factor affecting materials lubricant sensitivity. Fragmenting materials could be less sensitive to magnesium stearate because of the creation of smaller particles and lubricant-free surfaces during compression. In contrast, plastically deforming materials suffer from a high lubricant sensitivity since the lubricant film is not destroyed during consolidation.

Magnesium stearate as hydrophobic material may retard the drug dissolution from a solid dosage form and therefore, the lowest possible concentration is used in tablet and capsule formulations (Kato et al., 2005; Ndindayino et al., 1999; Rao et al., 2005). Bolhuis et al. (2009) stated that since xylitol and sorbitol are highly soluble compounds and tablets made of them disintegrate mainly by erosion, the dissolution of drug substance is less affected by magnesium stearate. Knowing the sticking propensity of these polyols, relatively high amount of lubricant is typically used in the studies. For both xylitol and sorbitol, sticking at 1\% magnesium stearate content has been reported (Morris et al., 1996; Saniocki et al., 2013). With an increase in the lubricant concentration from $2 \%$ to $4 \%$, a decrease in the sorbitol tablet tensile strength was observed (Saniocki et al., 2013).

Previously, it has not been studied how the relative humidity affects xylitol-sorbitol powder blends and tablets. It is well known that magnesium stearate can be used to prevent sticking during tableting. In industrial tablet manufacture, typically used magnesium stearate range is $0.25-5 \%$ according to Handbook of pharmaceutical excipients considered as a guide to the use of excipients (Allen and Luner, 2009). Usually, the amount of magnesium stearate used in the studies is at most $1-2 \%$. In this study, the focus was merely on the higher lubricant concentration range, $2-5 \%$, because of the preliminary studies showing sticking at $1 \%$ magnesium stearate concentration and the previous studies supporting these findings (Morris et al., 1996; Saniocki et al., 2013). The effect of this high magnesium stearate content on polyol tablets has not previously been evaluated. The aim of the study was to investigate how the formulation of chewable xylitol-sorbitol tablets affects the properties of the powder blends and the tablets in an environment of different relative humidity levels. It was also studied if a large amount of magnesium stearate (2-5\%) could be used in formulation to prevent sticking during tablet compression without compromising the compact strength.

\section{Materials}

Xylitol granulated with $\leq 2 \%$ sodium carboxymethylcellulose (Xylitol DC, Zhejiang Huakang Pharmaceutical Co., China) and sorbitol (Sorbitol TFF, Ecogreen Oleochemicals, Singapore) were used as filler- binders for the preparation of directly compressible powder blends. The powder blends were lubricated with magnesium stearate (Ligamed MF-2-V, Peter Greven GmbH, Bad Münstereifel, Germany) having a specific surface area of $7.8 \mathrm{~m}^{2} / \mathrm{g}$.

\section{Methods}

\subsection{Physical characterization of xylitol and sorbitol}

The particle size of xylitol and sorbitol batches was determined using a spatial filtering technique (IPP 70-Se-B, Parsum GmbH, Chemnitz, Germany). In spatial filtering, particle size is determined as the particles suspended in a gas stream pass through a laser beam, casting shadows onto a linear array of optical fibers. The principles of technique are presented by Aizu and Asakura (1987). Particle morphology was visualized by scanning electron microscopy (SEM) (FEI Quanta 250 FEG, FEI Inc., OR, USA) at an accelerating voltage of $5 \mathrm{kV}$. Bulk and tapped densities were determined at each level of relative humidity according to the European Pharmacopoeia 2.9.34., method one, measurement in a graduated cylinder (Erweka SVM 1UZ, Erweka Apparatebau GmbH, Heusenstamm, Germany). The powder flow was characterized at all three levels of relative humidity using two methods described in the European Pharmacopoeia: Flowability (Ph.Eur. 2.9.16.) and angle of repose (Ph.Eur. 2.9.36.). $100.0 \mathrm{~g}$ of the powder blend was loaded into a dry funnel, whose bottom opening was blocked by suitable means. The funnel had a diameter of $10 \mathrm{~mm}$.

Water activity and moisture content affect chemical and physical factors of raw materials and products during manufacturing and storage. There is a nonlinear relationship between water content and water activity, known as the moisture isotherm. Water activity $\left(\mathrm{A}_{\mathrm{w}}\right)$ value as a measure of unbound, free water in a system, gives a better indication about water's ability to function as a reactant and solvent than loss on drying (LOD) determination (Bell, 2007). Determination of $A_{w}$ is widely used especially in food industry to gain information whether there is sufficient moisture available to support the growth of micro-organisms. Water activity provides information about the direction of water movement in respect to surrounding $A_{\mathrm{W}}$ or relative humidity (Bell, 2007). Knowledge of the direction of water movement is useful e.g. in systems containing multiple components and moisture sensitive materials.

According to Ph.Eur. (2.2.32.) loss on drying is the loss of mass expressed as per cent $\mathrm{m} / \mathrm{m}$. Sartorius MA 100 (Sartorius AG, Goettingen, Germany) was used for the determination of LOD. The measurements were carried out by subjecting of sample to constant heating at $80{ }^{\circ} \mathrm{C}$ until the constant weight was reached. The results of $A_{w}$ were obtained using Aqualab 3 TE (Decagon Devices, Inc., Washington, USA) based on chilled mirror dew point technology. Water activity is measured by equilibrating the liquid-phase water in the sample with the vapor-phase water in the headspace, and then measuring the relative humidity of the headspace. When the water activity of the sample and the relative humidity of the air are in equilibrium, water condenses on a chilled mirror. Measurement of the headspace humidity gives the water activity of the sample. LOD and $A_{w}$ values of xylitol and sorbitol were determined after exposing a thin layer of the powders for at least twelve hours to three different relative humidity levels (RH); 20\% (13-25\%), 40\% (39-45 RH $\%)$ and $60 \%$ (58-66 $\mathrm{RH} \%)$. At $20 \mathrm{RH} \%$ the temperature range was $22-26{ }^{\circ} \mathrm{C}$ and at $40 \mathrm{RH} \%$ and $60 \mathrm{RH} \%$ the temperature range was 28-31 ${ }^{\circ} \mathrm{C}$. These were the conditions in which the exposure of raw materials, tableting and subsequent characterisation of tablets was carried out. $40 \mathrm{RH} \%$ and $60 \mathrm{RH} \%$ conditions were reached by using an artificial humidifier and manufacturing of the batches at $20 \mathrm{RH} \%$ was carried out in the same premises but in ambient conditions.

\subsection{Preparation of powder blends}

The effects of the amount of sorbitol, amount of magnesium stearate 
and relative humidity were evaluated employing three-level full-factorial design (Table 1a). The design contained 27 experiments and three center point replications resulting in a total of 30 experiments (Table $1 \mathrm{~b}$ ). Nine powder blends with varying proportions of xylitol, sorbitol and magnesium stearate were tested at three levels of relative humidity; $20 \%, 40 \%$ and $60 \%$. The amount of xylitol was dependent on the amount of sorbitol and magnesium stearate being in the most cases the main ingredient of the blend. The center point was located at the factorial combination of $(0,0,0)$. The center point batches contained $3.5 \%$ magnesium stearate, $35 \%$ sorbitol and they were exposed to $40 \mathrm{RH}$ $\%$. The relative humidity was kept constant at set levels, but the run order of each set of the experiments was randomized to prevent any type of bias.

Prior to mixing, the raw materials were exposed to the environmental conditions for at least twelve hours as described in Section 3.1. The masses of each batch with a size of $500 \mathrm{~g}$ were blended in a Turbula mixer at a speed of $46 \mathrm{rpm}$ (Model T2C, W.A. Bachofen, Basel, Switzerland). Sorbitol and xylitol were weighed and sieved with a $1 \mathrm{~mm}$ sieve and mixed for five minutes. After addition of magnesium stearate to powder blend, mixing was continued for two more minutes. After mixing, the powder blends were placed in a plastic jar made of polyethylene. The batch formulas are shown in Table $1 \mathrm{~b}$.

\subsection{Characterization of powder blends}

Selected powder blends were visualized by SEM imaging. Bulk and tapped densities were determined according to Ph.Eur. 2.9.34., method one. Flowability (Ph.Eur. 2.9.16.) and angle of repose (Ph.Eur. 2.9.36.) of the powder blends were determined. $A_{w}$ and LOD values of the blended masses were established.

\subsection{Compaction of tablets}

Tableting of powder blends and subsequent characterization of tablets was carried out in the same premises and conditions as the exposure of the raw materials (Section 3.1). The powder blends were made into tablets using an instrumented eccentric single-punch tablet press (Korsch EK0, Erweka Apparatebau GmbH, Heusenstamm, Germany) equipped with a flat-faced tooling set of $7 \mathrm{~mm}$ diameter. The compression speed was set to $61 \mathrm{rpm}$. Dwell time ( $\geq 90 \%$ of the peak value of compression force), was recorded to be $15-22 \mathrm{~ms}$ depending on the compression force. The shortest dwell times were measured with the lowest compression forces and the longest dwell times with the highest compression forces. Tableting process parameters were adjusted to obtain uniform tablet weight and breaking strength. The weight of the tablets was adjusted to $150 \mathrm{mg}$ and the breaking strength to $50 \mathrm{~N}$. The required compression force to obtain tablets with target breaking strength was recorded to evaluate the effect of the variables on tablets. The upper punch force, lower punch force and ejection force were recorded during tableting process and data from tablets 1-5 was used for compression force modeling. From each batch, 500 tablets were collected in sets of 100 tablets. Tablets number 101-200 were used for characterization of tablets. Sticking as phenomenon was visually evaluated from tablets $401-500$.

\subsection{Characterization/analysis of tablets}

The tablets were characterized immediately after manufacturing. Tablet weight $(n=20)$ and resistance to crushing force (Ph.Eur 2.9.8.) of tablets $(n=20)$ were determined (Schleuniger 2E, Dr. Schleuniger Pharmatorn AG, Solothurn, Switzerland). Tablet height and width ( $\mathrm{n}=$

Table 1

a) Factor levels.

\begin{tabular}{|c|c|c|c|c|c|c|}
\hline \multicolumn{2}{|c|}{ Factor levels } & Sorbitol (\%) & \multicolumn{2}{|c|}{ Magnesium stearate (\%) } & \multicolumn{2}{|r|}{ Relative humidity (\%) } \\
\hline-1 & & 20 & 2 & & & 20 \\
\hline 0 & & 35 & 3.5 & & & 40 \\
\hline 1 & & 50 & 5 & & & 60 \\
\hline \multicolumn{7}{|c|}{ b) Batch names, factor levels and composition of 30 batch formulations. } \\
\hline Batch & Sorbitol level & Magnesium stearate level & Relative humidity level & Xylitol (g) & Sorbitol (g) & Magnesium stearate $(\mathrm{g})$ \\
\hline N13 & 0 & 0 & -1 & 307.5 & 175 & 17.5 \\
\hline $\mathrm{N} 22$ & 1 & 0 & -1 & 232.5 & 250 & 17.5 \\
\hline N4 & -1 & 0 & -1 & 382.5 & 100 & 17.5 \\
\hline N25 & 1 & 1 & -1 & 225 & 250 & 25 \\
\hline N10 & 0 & -1 & -1 & 315 & 175 & 10 \\
\hline N1 & -1 & -1 & -1 & 390 & 100 & 10 \\
\hline N19 & 1 & -1 & -1 & 240 & 250 & 10 \\
\hline N16 & 0 & 1 & -1 & 300 & 175 & 25 \\
\hline N7 & -1 & 1 & -1 & 375 & 100 & 25 \\
\hline $\mathrm{N} 2$ & -1 & -1 & 0 & 390 & 100 & 10 \\
\hline N30 & 0 & 0 & 0 & 307.5 & 175 & 17.5 \\
\hline N29 & 0 & 0 & 0 & 307.5 & 175 & 17.5 \\
\hline N8 & -1 & 1 & 0 & 375 & 100 & 25 \\
\hline $\mathrm{N} 20$ & 1 & -1 & 0 & 240 & 250 & 10 \\
\hline N14 & 0 & 0 & 0 & 307.5 & 175 & 17.5 \\
\hline N28 & 0 & 0 & 0 & 307.5 & 175 & 17.5 \\
\hline N5 & -1 & 0 & 0 & 382.5 & 100 & 17.5 \\
\hline $\mathrm{N} 23$ & 1 & 0 & 0 & 232.5 & 250 & 17.5 \\
\hline N17 & 0 & 1 & 0 & 300 & 175 & 25 \\
\hline N11 & 0 & -1 & 0 & 315 & 175 & 10 \\
\hline N26 & 1 & 1 & 0 & 225 & 250 & 25 \\
\hline N3 & -1 & -1 & 1 & 390 & 100 & 10 \\
\hline N24 & 1 & 0 & 1 & 232.5 & 250 & 17.5 \\
\hline N9 & -1 & 1 & 1 & 375 & 100 & 25 \\
\hline N27 & 1 & 1 & 1 & 225 & 250 & 25 \\
\hline $\mathrm{N} 21$ & 1 & -1 & 1 & 240 & 250 & 10 \\
\hline N6 & -1 & 0 & 1 & 382.5 & 100 & 17.5 \\
\hline N12 & 0 & -1 & 1 & 315 & 175 & 10 \\
\hline N18 & 0 & 1 & 1 & 300 & 175 & 25 \\
\hline N15 & 0 & 0 & 1 & 307.5 & 175 & 17.5 \\
\hline
\end{tabular}


10) as an average of two perpendicular measurements were determined using a digital micrometer (Sony U30-F digital indicator, Sony Magnescale Inc., Japan). Friability of the tablets was determined according to Ph.Eur. 2.9.7. (Sotax Friabilator CH-4123, Allschwill/Basel, Switzerland). The punch surfaces were visually inspected after compaction and any visible matter was considered as sticking (on/off). SEM images of selected batches were taken.

\subsection{Modeling}

Modeling was performed using Modde for Windows (Version 7.0, Umetrics, Umeå, Sweden), applying a stepwise regression technique. The effects of the process variables were then modeled, using a secondorder polynomial fitting (Eq. (1)). The models were simplified with a multilinear backwards, stepwise regression technique. The least significant terms were excluded from the model as long as the predictive power $\left(Q^{2}\right)$ of the model increased.

$$
\begin{aligned}
Y= & a_{1} \cdot H u m+a_{2} \cdot M g S+a_{3} \cdot \text { Sor }+a_{4} \cdot H u m \cdot M g S+a_{5} \cdot H \text { um } \cdot \text { Sor }+a_{6} \cdot M g S \cdot \text { Sor } \\
& +a_{7} \cdot H u m^{2}+a_{8} \cdot M g S^{2}+a_{9} \cdot \text { Sor }^{2}+c
\end{aligned}
$$

where $Y=$ response, Hum $=$ humidity of the air, $M g S=$ amount of magnesium stearate and Sor $=$ amount of sorbitol. $a_{1} \ldots a_{9}$ are coefficients and $c=$ constant.

\section{Results and discussion}

\subsection{Modeling}

Full factorial design $\left(3^{3}\right)$ provides information about every main effect and every interaction effect thus enabling the use of quadratic models. Second-order polynomial equations were able to describe the process behaviour although highly non-linear responses were observed. The equations for each response are presented in dataset (Juvonen, 2021). Logarithmic transformation was used for several response data to make them normally distributed. $R^{2}$ (goodness of fit) and $Q^{2}$ (predictive accuracy) values are found in the figure caption of each model. Mostly, the $R^{2}$ and $Q^{2}$ values indicated high goodness of fit and the models had predictive relevance. The lowest but still acceptable $R^{2}$ and $Q^{2}$ values were for angle of repose model (Fig. 3) being 0.72 and 0.52 , respectively. This was connected to the nature of the angle of repose measurement method showing variability in repeatability. In all models, the

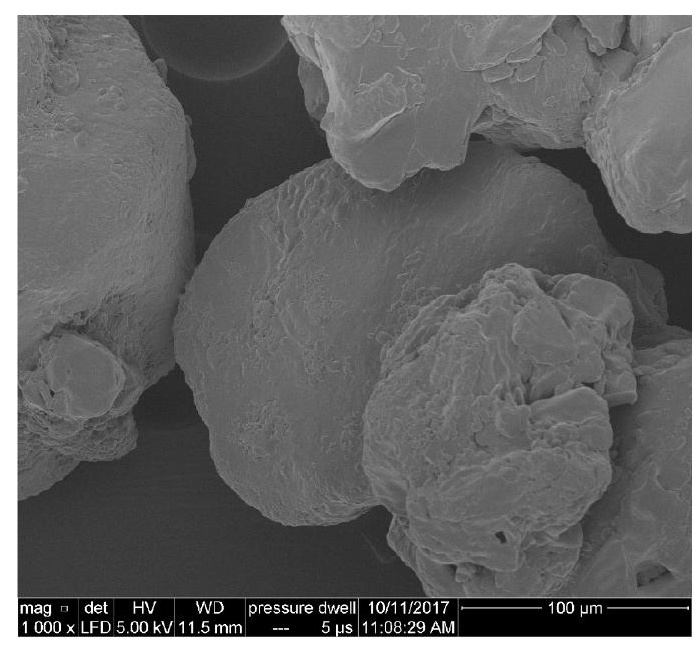

(b)

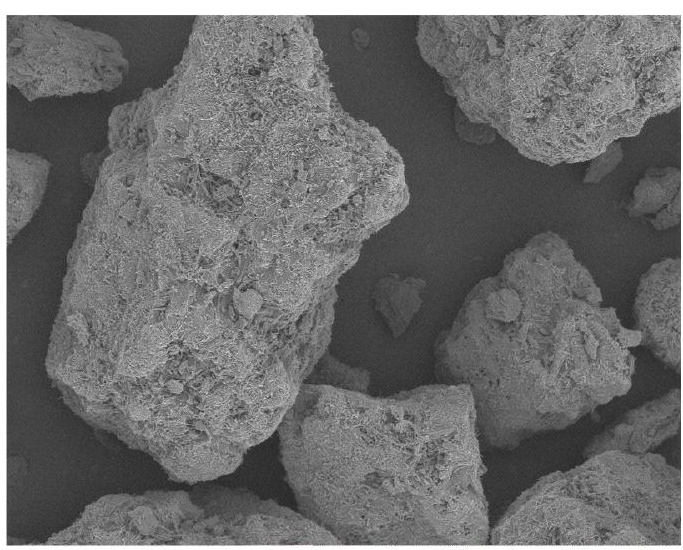

Fig. 1. SEM images of xylitol at (a) 200x and (b) 1000x magnification. SEM images of sorbitol (c) $200 \times$ and (d) $1000 \times$ magnification. 
residuals were normally distributed proving the models fit for the data. Response surface modeling can be used if the response can be described with a second order polynomial equation (Baş and Boyac1, 2007). The response surface methodology was used in this study to evaluate the effect of factors, also enabling the optimization.

Measured relative humidity values at $20 \mathrm{RH} \%$ had relatively high fluctuation since the manufacturing of the batches was carried out in ambient conditions. Conditions of $40 \mathrm{RH} \%$ and $60 \mathrm{RH} \%$ were more steadily reached by using an artificial humidifier. Because of the fluctuation in the moisture it was not possible to carry out analysis of variance (ANOVA) but the fluctuation was taken into consideration in the data analysis.

\subsection{Xylitol and sorbitol}

The SEM images taken from the raw materials revealed that the surface structure of xylitol was smooth whereas sorbitol had a rough surface consisting of crystalline material. When comparing the particle shape with the same magnification, the shape of sorbitol particles appeared to be more symmetrical and spherical than those of xylitol (Fig. 1). The particles of xylitol were coarser than those of sorbitol. The D10, D50 and D90 values for xylitol were $200 \pm 4 \mu \mathrm{m}, 365 \pm 6 \mu \mathrm{m}$ and $614 \pm 33 \mu \mathrm{m}$, respectively and for sorbitol $70 \pm 1 \mu \mathrm{m}, 149 \pm 5 \mu \mathrm{m}$ and $285 \pm 15 \mu \mathrm{m}$, respectively.

The physical characteristics of xylitol and sorbitol are presented in Table 2. Many factors influence powder flowability, such as particle size, shape and density of the particles. In general, large, spherical and dense particles are desirable in the sense of flowability. Sorbitol had a higher density than xylitol and its flowability was better regarding both the flow time and the angle of repose values. Neither xylitol nor sorbitol flew through an orifice at $60 \mathrm{RH} \%$ and therefore the angle of repose was not recordable. The $\mathrm{A}_{\mathrm{w}}$ values of the raw materials were rather similar but the LOD values differed from each other at $40 \mathrm{RH} \%$ and $60 \mathrm{RH} \%$. Each material has a unique relationship between moisture content and water activity called moisture sorption isotherm. Isotherm is temperature and pressure dependent and looks different whether it is obtained by drying or wetting the sample. Usually, both Aw and LOD increase with increasing RH but the relationship of Aw and LOD is non-linear. Typically, crystalline materials gain very small amounts of moisture up to the deliquescence point (RH0), which is also characteristic of xylitol and sorbitol (Lipasek et al., 2013; Nezzal et al., 2009).

Table 2

Physical characteristics of xylitol and sorbitol.

\begin{tabular}{|c|c|c|c|c|c|c|c|}
\hline & $\begin{array}{l}\text { RH } \\
(\%)\end{array}$ & $\begin{array}{l}\text { Bulk } \\
\text { density } \\
(\mathrm{g} / \mathrm{ml})\end{array}$ & $\begin{array}{l}\text { Tapped } \\
\text { density } \\
(\mathrm{g} / \mathrm{ml})\end{array}$ & $\begin{array}{l}\text { Flow } \\
\text { time } \\
(\mathrm{s} / 100 \\
\mathrm{g})\end{array}$ & $\begin{array}{l}\text { Angle } \\
\text { of } \\
\text { repose } \\
\left({ }^{\circ}\right)\end{array}$ & $\begin{array}{l}\text { LOD } \\
(\%)\end{array}$ & $\mathrm{A}_{\mathrm{w}}$ \\
\hline \multirow[t]{3}{*}{ Xylitol } & 20 & $\begin{array}{l}0.52 \pm \\
0.01\end{array}$ & $\begin{array}{l}0.60 \pm \\
0.01\end{array}$ & $\begin{array}{l}8.88 \pm \\
0.5\end{array}$ & $\begin{array}{l}36.3 \pm \\
0.2\end{array}$ & $\begin{array}{l}0.14 \\
\pm \\
0.02\end{array}$ & $\begin{array}{l}0.06 \\
\pm \\
0.01\end{array}$ \\
\hline & 40 & $\begin{array}{l}0.52 \pm \\
0.01\end{array}$ & $\begin{array}{l}0.57 \pm \\
0.01\end{array}$ & $\begin{array}{l}12.82 \\
\pm 3.0\end{array}$ & $\begin{array}{l}35.9 \pm \\
0.1\end{array}$ & $\begin{array}{l}0.17 \\
\pm \\
0.03\end{array}$ & $\begin{array}{l}0.14 \\
\pm \\
0.04\end{array}$ \\
\hline & 60 & $\begin{array}{l}0.47 \pm \\
0.01\end{array}$ & $\begin{array}{l}0.48 \pm \\
0.01\end{array}$ & no flow & no flow & $\begin{array}{l}0.82 \\
\pm \\
0.02\end{array}$ & $\begin{array}{l}0.51 \\
\pm \\
0.01\end{array}$ \\
\hline \multirow[t]{3}{*}{ Sorbitol } & 20 & $\begin{array}{l}0.61 \pm \\
0.01\end{array}$ & $\begin{array}{l}0.68 \pm \\
0.01\end{array}$ & $\begin{array}{l}3.52 \pm \\
0.4\end{array}$ & $\begin{array}{l}27.3 \pm \\
0.1\end{array}$ & $\begin{array}{l}0.19 \\
\pm \\
0.01\end{array}$ & $\begin{array}{l}0.06 \\
\pm \\
0.01\end{array}$ \\
\hline & 40 & $\begin{array}{l}0.59 \pm \\
0.01\end{array}$ & $\begin{array}{l}0.64 \pm \\
0.01\end{array}$ & $\begin{array}{l}4.03 \pm \\
0.1\end{array}$ & $\begin{array}{l}27.9 \pm \\
0.1\end{array}$ & $\begin{array}{l}0.49 \\
\pm \\
0.03\end{array}$ & $\begin{array}{l}0.23 \\
\pm \\
0.01\end{array}$ \\
\hline & 60 & $\begin{array}{l}0.49 \pm \\
0.01\end{array}$ & $\begin{array}{l}0.51 \pm \\
0.01\end{array}$ & no flow & no flow & $\begin{array}{l}2.49 \\
\pm \\
0.03\end{array}$ & $\begin{array}{l}0.55 \\
\pm \\
0.03\end{array}$ \\
\hline
\end{tabular}

Fig. 2. Model of tapped density at different relative humidity levels as a function of formulation variables $\left(R^{2}=0.90, Q^{2}=0.86\right)$.

\subsection{Powder blends}

\subsubsection{Bulk and tapped density}

Increase in humidity decreased both bulk and tapped densities of the powder blends. The decrease in tapped density was pronounced at 60 $\mathrm{RH} \%$ as seen in Fig. 2. For soluble materials, multilayers of water and capillary condensation lead to surface dissolution and liquid bridging between the particles and the changes in particle surface may occur already below the material specific relative humidity where the deliquescence occurs (RHO) (Ahlneck and Alderborn, 1989; Schubert, 1984). According to literature, the RH0 values of xylitol and sorbitol are 80-85 RH\%/25 ${ }^{\circ} \mathrm{C}$ and $65-70 \mathrm{RH} \% / 25^{\circ} \mathrm{C}$, respectively (Lipasek et al., 2013; Nezzal et al., 2009). Mixtures consisting of two or more deliquescent components undergo deliquescence at lower relative humidity than the corresponding separate raw materials (Lipasek et al., 2013; Salameh and Taylor, 2005). Xylitol and sorbitol and are highly soluble and deliquescent compounds and therefore, at high humidity, the surface of the particles may become partially solubilized and cause tackiness. Lumping of the powder blend may occur due to the high viscosity liquid bridges. Especially, sorbitol has a strong thickening power i.e. ability to form strong liquid bridges due to the high viscosity of the saturated aqueous solution (Santomaso et al., 2017). Liquid bridges are reported to limit optimum packing of the material and thus decrease the bulk density (Armstrong et al., 2014; Peleg et al., 1973).

Powder blends had higher bulk and tapped densities than xylitol or sorbitol separately. The packing of powder blends was different from the raw materials because the interparticle voids could be filled with smaller particles. With increasing proportion of sorbitol, the density of the powder blends increased, as expected, because of the higher density of sorbitol in comparison to xylitol. Likewise, magnesium stearate had a density increasing effect on the powder blends. The thin layer on the powder particles formed by magnesium stearate decreased the interparticle friction between particles leading to a higher packing density. Formation of lubricant film can be clearly observed in dataset (Juvonen, 2021).

\subsubsection{Powder flow}

Based on the flow time and angle of repose measurements it was seen that the powder flow properties deteriorated as the humidity increased (Fig. 3), which is typical of hygroscopic powders (Juarez-Enriquez et al., 2017). When powder is in contact with atmospheric humidity, water vapour is adsorbed first as non-freely moveable monolayers and, with increasing surrounding humidity, as more moveable, solvent-like multilayers (Zografi, 1988). At conditions favorable for capillary 


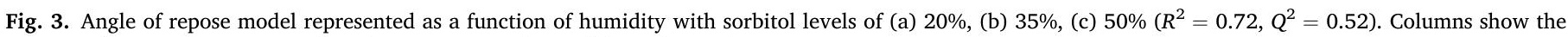
amount of magnesium stearate. Error bars represent the confidence intervals.

condensation, liquid bridges will first form at the contact points of particles or adsorption layers (Schubert, 1984). The formation of liquid bridges causes the increase in cohesion and can strongly affect the powder flow (Billings et al., 2006; Schubert, 1984). The flow time was also affected by decreased bulk density since the volume flowing through an orifice was larger but apparently the underlying reason, surface wetting and formation of cohesion increasing liquid bridges, was common. Anyhow, the flowability of all the powder blends at all humidity levels could be regarded as good to excellent according to the results of angle of repose determination (Ph.Eur. 2.9.16.), all of them being below $35^{\circ}$, whereas xylitol and sorbitol did not flow at all at $60 \mathrm{RH}$ $\%$ (Table 2).

Sorbitol had better flow properties than xylitol. Hence, increasing proportion of sorbitol increased the flowability. Looking at the results of angle of repose, the better flowability of powder blends in respect of raw materials was largely seen as an effect of magnesium stearate, i.e. magnesium stearate acting as a glidant in powder blends (Fig. 3). The SEM pictures revealed that the surface roughness of polyol particles was smoothened out with layers of magnesium stearate, as shown in dataset (Juvonen, 2021), therefore facilitating the flow of the powder blend.

The overlap of $83 \%$ confidence intervals was used as a method for assessing whether two means were significantly different from one another at the 5\% confidence level (Austin and Hux, 2002). This approach based on the model was used instead of ANOVA because there was fluctuation in the moisture levels as introduced in Section 4.1 and the fluctuation was taken into account in the model. At $20 \mathrm{RH} \%$, no statistical difference in angle of repose was detected with increasing amount of magnesium stearate.

At $40 \mathrm{RH} \%$ and $60 \mathrm{RH} \%$, the increase of magnesium stearate from $2 \%$ to $3.5 \%$ or $5 \%$ improved the powder flow. With increasing humidity, more magnesium stearate was needed for optimum flowability due to tackiness of the particles. In addition to showing a glidant effect, magnesium stearate also exhibits anti-caking properties by decreasing the direct contact between polyol particles and preventing the formation of liquid bridges. Lipasek et al. (2012) reported that addition of anticaking agent (calcium stearate) to binary mixture of deliquescent compounds maintained the flowability.

Deliquescence takes place at a characteristic relative humidity (RH0), which corresponds to the vapor pressure of saturated solution of the substance (Van Campen et al., 1983). If there are two or more deliquescent compounds present in the mixture, the deliquescence occurs at lower relative humidity level than the RHO of separate raw materials (Salameh and Taylor, 2005; Salameh et al., 2006). This phenomenon is called deliquescence lowering. The mixtures of deliquescent compounds exhibit greater hygroscopicity at high $\mathrm{RH}$ in comparison to the separate raw materials (Salameh et al., 2006). From that point of view, the effect of magnesium stearate on a mixture of xylitol and sorbitol is substantial as the flowability is maintained even at $60 \mathrm{RH} \%$ which is close to sorbitol's deliquescence point.

\subsubsection{Water activity and loss on drying}

The level of $A_{w}$ values of the powder blends increased with increasing relative humidity, as expected (Fig. 4). The $A_{W}$ values of xylitol and sorbitol were similar to each other at different relative humidity levels, and therefore their effect could not be differentiated (Table 2). Magnesium stearate had only a small nonlinear impact on $A_{w}$ values. The minimum $A_{W}$ enabling the growth of micro-organisms is 0.60 (Beuchat et al., 2013). The water activity of maximum 0.4 was

Fig. 4. Model of $A_{\mathrm{w}}$ values represented as a function of relative humidity $\left(R^{2}=\right.$ $0.97, Q^{2}=0.97$ ). The $95 \%$ confidence interval is visualized with green and blue lines. 


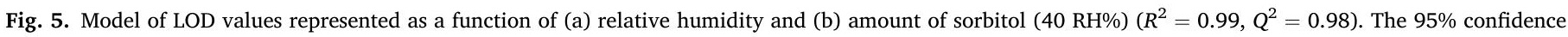
interval is visualized with green and blue lines.

reached at $60 \mathrm{RH} \%$ indicating that there was not sufficient moisture to support the growth of micro-organisms.

At $20 \mathrm{RH} \%$ the LOD values remained low but as the RH increased the LOD value increased exponentially (Fig. 5). As a consequence of increase in the amount of sorbitol a slight increase in LOD value was seen at all humidity levels because sorbitol has a stronger hygroscopic ability than xylitol (Bolhuis et al., 2009).

Table 3

Breaking strength of tablets in the beginning of tableting $(n=5)$ and tablets $101-200(\mathrm{n}=10)$.

\begin{tabular}{lll}
\hline Batch & Beginning of tableting $(\mathrm{N})$ & Tablets $101-200(\mathrm{~N})$ \\
\hline N13 & $50.8 \pm 7.8$ & $66.0 \pm 8.3$ \\
N22 & $50.2 \pm 2.6$ & $58.2 \pm 2.6$ \\
N4 & $49.9 \pm 2.1$ & $58.3 \pm 5.3$ \\
N25 & $49.3 \pm 2.2$ & $46.7 \pm 1.6$ \\
N10 & $49.3 \pm 0.5$ & $35.0 \pm 4.4$ \\
N1 & $52.3 \pm 2.9$ & $28.4 \pm 7.2$ \\
N19 & $50.0 \pm 2.8$ & $52.4 \pm 8.3$ \\
N16 & $50.7 \pm 2.7$ & $55.4 \pm 4.8$ \\
N7 & $50.7 \pm 2.8$ & $32.3 \pm 6.1$ \\
N2 & $48.7 \pm 6.4$ & $51.1 \pm 5.3$ \\
N30 & $49.0 \pm 5.6$ & $60.2 \pm 6.0$ \\
N29 & $49.4 \pm 6.5$ & $51.4 \pm 4.0$ \\
N8 & $50.8 \pm 0.8$ & $47.8 \pm 3.8$ \\
N20 & $50.7 \pm 1.6$ & $41.3 \pm 4.6$ \\
N14 & $49.4 \pm 2.5$ & $62.6 \pm 1.4$ \\
N28 & $49.6 \pm 2.3$ & $52.4 \pm 3.3$ \\
N5 & $50.6 \pm 1.6$ & $50.8 \pm 5.2$ \\
N23 & $49.4 \pm 3.1$ & $53.0 \pm 2.3$ \\
N17 & $49.5 \pm 3.9$ & $53.3 \pm 2.1$ \\
N11 & $50.0 \pm 5.3$ & $60.2 \pm 3.2$ \\
N26 & $49.3 \pm 2.2$ & $52.7 \pm 1.5$ \\
N3 & $46.7 \pm 1.5$ & $48.9 \pm 3.1$ \\
N24 & $49.8 \pm 3.4$ & $48.7 \pm 1.3$ \\
N9 & $40.0 \pm 3.8$ & $42.0 \pm 3.5$ \\
N27 & $49.3 \pm 2.8$ & $48.5 \pm 3.9$ \\
N21 & $49.0 \pm 1.4$ & $50.7 \pm 4.3$ \\
N6 & $41.3 \pm 3.5$ & $43.5 \pm 7.1$ \\
N12 & $49.5 \pm 1.0$ & $51.5 \pm 3.3$ \\
N18 & $39.4 \pm 2.4$ & $41.3 \pm 3.0$ \\
N15 & $43.3 \pm 4.5$ & \\
\hline & & \\
\hline
\end{tabular}

\subsection{Tablets}

\subsubsection{Compression force}

In the beginning of tableting, breaking strength of tablets was set as close to $50 \mathrm{~N}$ as possible (Table 3). Since the tablet press was not equipped with an automatic weight controller, the breaking strength of the tablets number 101-200 differed from the preset value as presented in Table 3. Compression force i.e. upper punch force required to achieve the preset strength can be used as an indicator of how well the powder blend forms tablets. A low compression force required indicates good tabletability (breaking strength vs. pressure). Of all the three variables, humidity had the greatest impact on the compression force (Fig. 6). At $20 \mathrm{RH} \%$ and $40 \mathrm{RH} \%$, the compression force was at its lowest and with increasing humidity the compression force increased steeply. An increase in the moisture content reduced the tabletability of the powder blends and greater force was required to achieve the specified breaking strength.

In the study of Morris et al. (1996) capping of xylitol tablets was noticed after a certain border limit in compression force was reached. Garr and Rubinstein (1990) concluded that xylitol exhibited significant sensitivity to compression force. Increasing the compression force after reaching the maximum tensile strength resulted in a decrease in tensile strength due to elastic recovery. Nikolakakis et al. (2002) reported that the elastic recovery of sorbitol increased as the relative humidity was elevated from $23 \%$ to $69 \%$. In this study, at $20 \mathrm{RH} \%$ and $40 \mathrm{RH} \%$ no capping or decreased breaking strength was observed due to the relatively low compression forces. As a result of high humidity and high compression force, four of nine batches suffered from low compact strength apparently due to increased elastic recovery. The maximum compact strength of only $40 \mathrm{~N}$ was obtained for batches with low to middle amount of sorbitol and middle to high amount of magnesium stearate (Table 3). Lower tabletability of powder blends containing more xylitol was emphasized at high humidity leading to a conclusion that the compression properties of xylitol suffer more from moisture than those of sorbitol. Under high compression force the elastic recovery of tablets is extensive leading to the rupture of interparticle bonds and failure to form compacts of target strength.

As supposed, magnesium stearate had an overall negative effect on 

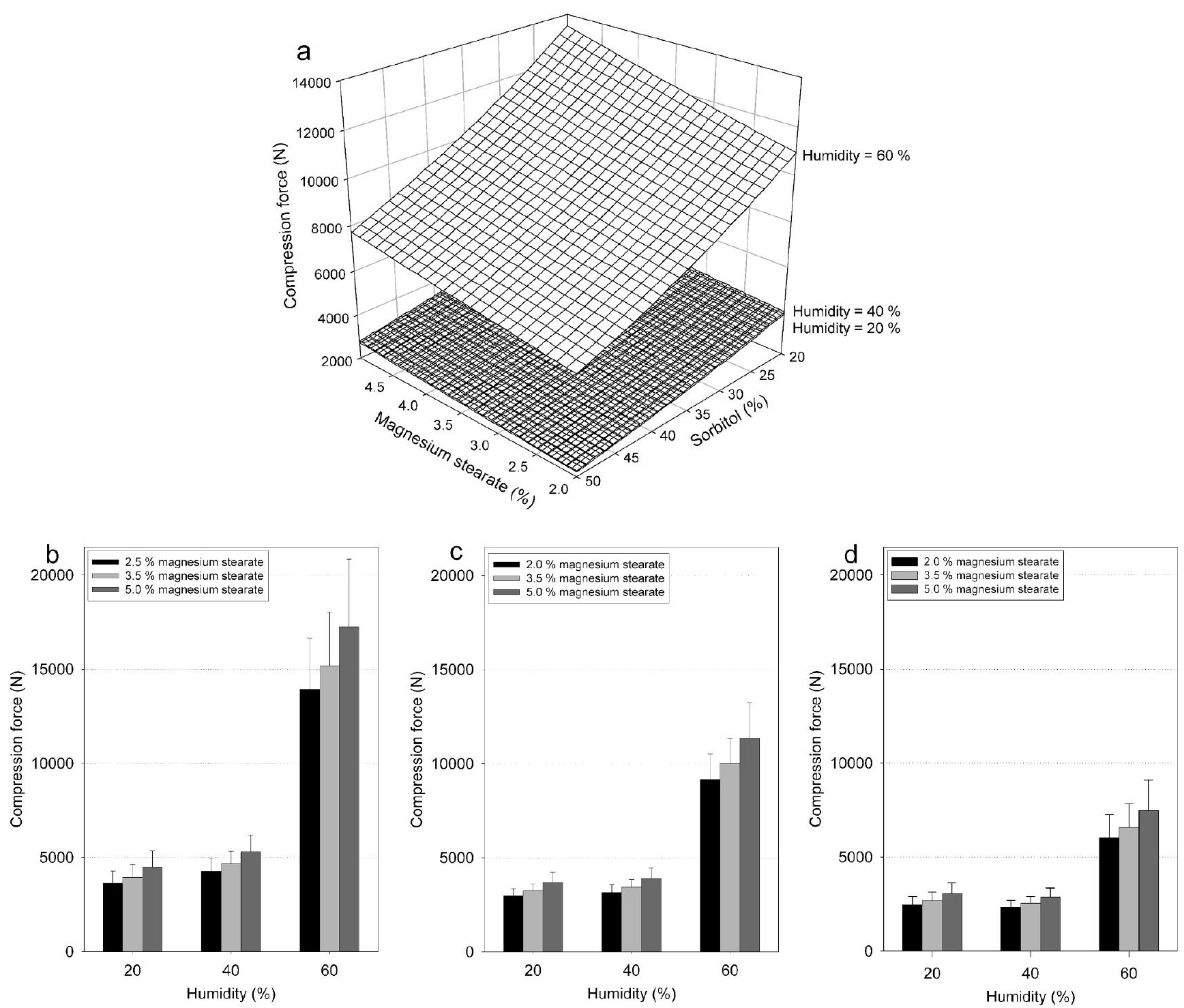

Fig. 6. a) Compression force visualized as a function of variables $\left(R^{2}=0.86, Q^{2}=0.79\right)$. Modeled compression force as a function of humidity with sorbitol level of b) $20 \%$ c) $35 \%$ and d) $50 \%$. The columns illustrate the amount of magnesium stearate. The error bars show the $95 \%$ confidence interval.

compression force. Compactibility of sorbitol has been reported to decrease in the presence of magnesium stearate (Kelemen, 2015). At high relative humidity, it was also noticed that especially the compaction properties of xylitol got worse on increasing amount of magnesium stearate. This indicates sensitivity to lubricant, although fragmentation is reported to be the main deforming mechanism of xylitol and therefore it should be less susceptible to overlubrication (Garr and Rubinstein, 1990). However, it has been reported that moisture has a plasticizing effect on pharmaceutical sugars (Li and Peck, 1990; Nikolakakis et al., 2002). Moreover, xylitol grade used in this study was coprocessed with NaCMC which is a cellulose derivative and exhibits amorphicity. Water acts as a plasticizer of amorphous regions making the material more mobile (Zografi, 1988). In this regard, NaCMC-xylitol may behave more plastically than pure xylitol at $60 \mathrm{RH} \%$. Increase in plasticity increases the sensitivity to lubricants which could explain part of the negative effect of magnesium stearate especially in combination with xylitol.

The deforming mechanism of sorbitol is primarily plastic, but the sorbitol grade used in this study consisted of particles having a porous structure which increases the fragmenting behavior and therefore fresh lubricant-free surfaces available for bonding are created (Fig. 1). Moreover, sorbitol had smaller particle size than xylitol thus having a larger surface area to participate in binding.

\subsubsection{Friability}

The friability of the tablets decreased steeply with increasing humidity (Fig. 7). High moisture content along with high compression force produced tablets with low friability values although the target breaking strength remained the same and was not reached in all the batches at $60 \mathrm{RH} \%$. The low friability was the consequence of moisturedriven increase in plasticity of the tablets and, to some extent, higher density and smaller surface area of the tablet as the particles were more closely packed (Li and Peck, 1990; Nikolakakis et al., 2002; Paul and Sun, 2018). Visually, the tablets compacted at high humidity were smooth and glossy and the tablets compacted at low humidity were powdery and matt. The SEM images presented in dataset (Juvonen, 2021) showed that at $60 \mathrm{RH} \%$ the surfaces of the tablets consisted of consolidated areas and cavities whereas the tablets compressed at $20 \mathrm{RH}$ $\%$ had more consistent but porous surface. Friability is often connected to compact strength, but it is also affected by several other factors like the deformation mechanism of raw materials, the tooling design, amount of lubricant and the lubrication time. In this study, the amount of lubricant did not affect the friability whereas sorbitol had a positive effect on it, especially at low relative humidity. 


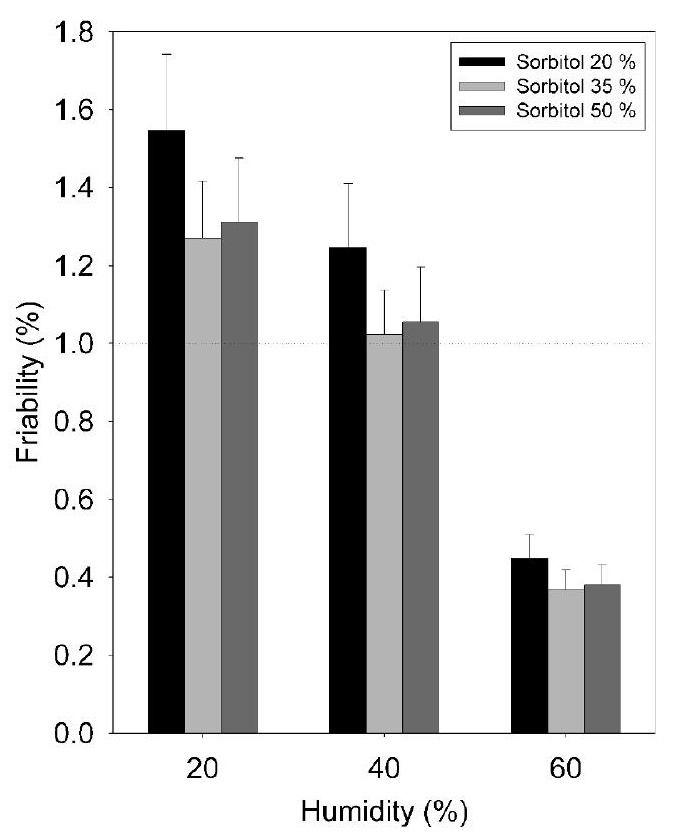

Fig. 7. Modeled friability presented as a function of different relative humidity levels $\left(R^{2}=0.91, Q^{2}=0.87\right)$. The amount of sorbitol is presented as columns. The $1 \%$ friability limit is demonstrated as an acceptance level for most products (Ph.Eur. 2.9.7.).

\subsubsection{Tableting at high humidity}

At lower humidity levels the tabletability of the powder blends proved to be almost insensitive to mixing with magnesium stearate although large amounts of lubricant were used. Increase in the amount of magnesium stearate mainly reduced the ejection force. Increase in humidity to $60 \mathrm{RH} \%$ induced the sticking of the tablet material to the upper punch. Even as large amount as $5 \%$ of magnesium stearate could not prevent the sticking as it appeared in six of nine batches. Three batches with the lowest LOD values did not stick, these being the batches with the lowest amount of sorbitol. Considering sorbitol's sorption isotherm, high solubility, wettability and strong thickening power, i.e. high viscosity of the saturated aqueous solution, it is expected that a high sorbitol load causes sticking close to its deliquescence point (Santomaso et al., 2017). It was found that a combination of high sorbitol content and high compression force caused the sticking. Previously, it has been concluded that high compression force may cause sticking due to increase in true contact area of plastically deforming materials (Abdel-Hamid and Betz, 2012; Waimer et al., 1999). High compression force was anyhow needed to form tablets of specified breaking strength at the presence of high relative humidity. The need for higher compression force was caused by the change in the compaction properties of the powder blends with increasing moisture content, e.g. due to the increase in elastic recovery (Garr and Rubinstein, 1990; Nikolakakis et al., 2002). The dominant bonding mechanisms between particles have been reported to be solid bridge formation, intermolecular forces, and mechanical interlocking (Karehill et al., 1990). At high humidity level water film may also disturb intermolecular forces and therefore lead to a need for higher compression force (Lordi and Shiromani, 1983).

Magnesium stearate affected negatively the bond formation within tablet especially in the presence of high humidity. With increasing humidity, the deformation mechanism of sorbitol and other pharmaceutical sugars generally turns towards more plastic (Li and Peck, 1990; Nikolakakis et al., 2002). It is known that plastically deforming materials have more tendency to stick and they are sensitive to lubrication (Bolhuis and Anthony Armstrong, 2006; Paul et al., 2017). Powder blends with low amount of sorbitol or high amount of xylitol were found to be sensitive to lubrication by magnesium stearate and weaker (than specification) tablets were produced at $60 \mathrm{RH} \%$. It is suggested that xylitol with larger particles is more sensitive to lubrication than sorbitol with smaller and porous particles.

High ejection force during tableting implies that the tablet is susceptible to defects such as capping, lamination or sticking (Uzondu et al., 2018). Since sticky powders elevate the die wall friction, ejection force has been used to evaluate the sticking tendency of the powder blends. However, the sticking tendency of sorbitol at high humidity could not be detected as a rise in ejection force. An optimal amount of magnesium stearate should not be exceeded to avoid issues with compact strength and dissolution. Ejection force was at its lowest at $40 \mathrm{RH} \%$ and $2.5 \%$ of magnesium stearate was found to be sufficient to keep the ejection force on the plateau level, indicating that there is no need for further lubrication (Fig. 8). The moisture content seemed to have a lubricating effect on the powder blends during tableting and the lowest amount of magnesium stearate was sufficient to keep the ejection force low. At $20 \mathrm{RH} \%$ and $60 \mathrm{RH} \%$ the ejection force increased steeply together with the amount of xylitol and the plateau level was reached with $3.5 \%$ of magnesium stearate. The increase in ejection force was connected to the need for higher compression force due to low tabletability of xylitol and increased plasticity of polyols at high humidity. Thapa et al. (2017) studied differently deforming materials and found that elastic and plastic granules exhibited stronger binding with the die, and therefore higher ejection force, than brittle granules. Generally, the increase of the compact die-wall friction tends to increase the die-wall pressure during compaction. The die-wall pressure, which is a contributing factor for the ejection force, is reported to increase on increasing compression force and tableting speed (Desbois et al., 2019; Sun, 2015).

Fig. 9 is a compilation of two contour plots and separately added sticking batches. The $R^{2}$ and $Q^{2}$ values of the respective models are presented in Fig. 6 (compression force) and Fig. 7 (friability). From the viewpoint of optimizing the formulation, it can be seen in Fig. 9 that there is rather a narrow range (gray area) of relative humidity where the friability stays below desirable $1 \%$ and still does not cause sticking to the punches. This indicates that it is necessary to use additional binders in combination with the studied raw materials to obtain tablets of good quality compressed within a wide relative humidity range. Use of additional binders would reduce the sticking at high humidity because of need for lower compression forces. The use of magnesium stearate could then be optimized in the sense of flowability and ejection force.

Since the effect of excipients on powder blend and tablet properties was studied, there was no active pharmaceutical ingredient (API) incorporated in the powder blends. It is suggested that incorporation of an API that is used at low dose would not alter the results. The formulation including an API used at high dose would need a dedicated study

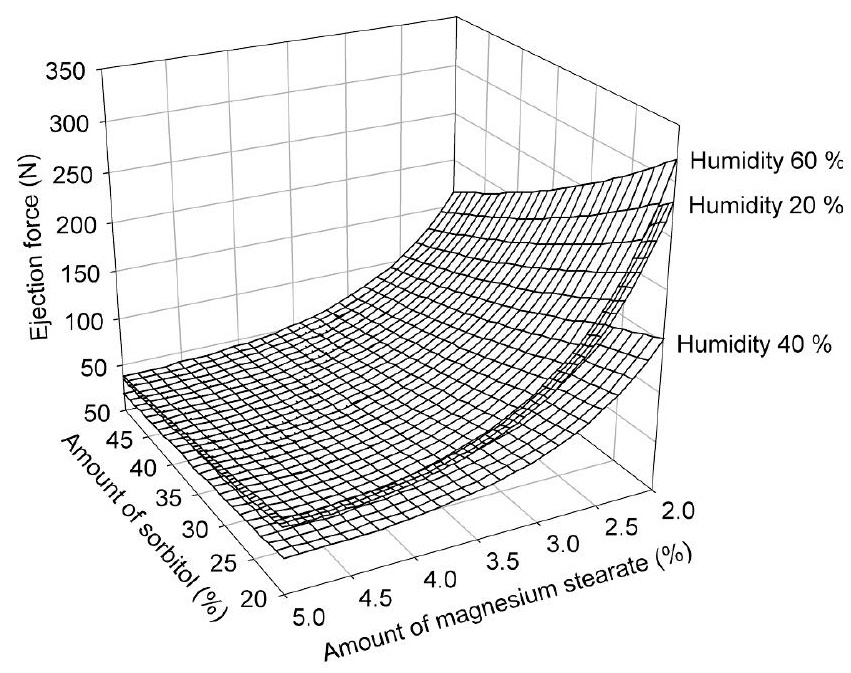

Fig. 8. The model of ejection force at different humidity levels as a function of formulation variables $\left(R^{2}=0.82, Q^{2}=0.71\right)$. 


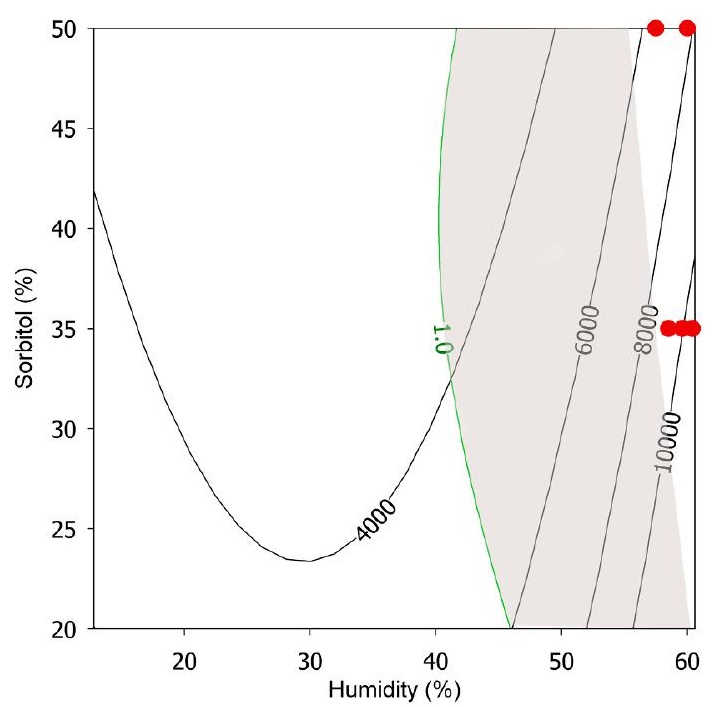

Fig. 9. Illustration of tablets of good quality on grey area, sticking batches (red dots) and 1\% friability level (green line). Different compression force (N) levels (black lines) are shown as a function of the amount of sorbitol and relative humidity level.

due to the major effect of API on the flow properties and the behaviour of powder blends under pressure.

Water can interact with crystalline material in several ways, e.g. hydrate formation, surface dissolution and deliquescence. Manufacturing of tablets consisting of soluble, crystalline materials at high humidity can lead to surface dissolution and formation of liquid bridges between particles (Schubert, 1984). It should be considered in future stability studies that during storage, subsequent recrystallisation of dissolved materials may occur and cause hardening of the tablets (Alderborn and Ahlneck, 1991; Lordi and Shiromani, 1983). Likewise, the effect of high magnesium stearate content on the possible hardening of the tablets is a subject of future investigation.

\section{Conclusion}

Apparently, xylitol-sorbitol based powder blends benefitted from large amount of magnesium stearate since it prevented the caking, enhanced the flowability and reduced the ejection force. Magnesium stearate content did not affect the friability negatively. The results indicated that even with a high amount of magnesium stearate $(5 \%)$ it was possible to produce xylitol-sorbitol based tablets of the specified compact strength, at $\mathrm{RH}$ up to $40 \%$, although the tablets showed relatively high friability $(<1.5 \%)$. Only at $60 \mathrm{RH} \%$, the friability was clearly below desired $1 \%$ limit. Increasing sorbitol content enhanced the compaction properties of the xylitol-sorbitol powder blends. At $60 \mathrm{RH} \%$, low amount of magnesium stearate was preferred along with high sorbitol content to obtain tablets with target compact strength and yet, high compression force was needed. On the other hand, high sorbitol content increased the LOD value of the powder blends and promoted sticking to the upper punch face. However, the elevation of the ejection force was caused by xylitol instead of sorbitol. At $60 \mathrm{RH} \%$, the sorbitol content must be limited to below $35 \%$ to prevent the sticking. Consequently, high xylitol content would lead to the use of even higher compression forces and might cause failure to form compacts due to poor tabletability. An overall conclusion is that, to obtain tablets of sufficient quality with these xylitol and sorbitol grades, additional fillers/binders are needed when operating within a wide relative humidity range.

\section{CRediT authorship contribution statement}

Henna Juvonen: Conceptualization, Investigation, Writing - original draft. Osmo Antikainen: Formal analysis, Visualization, Supervision. Marijke Lemmens: Investigation. Henrik Ehlers: Conceptualization, Methodology, Supervision. Anne Juppo: Conceptualization, Supervision, Writing - review \& editing.

\section{Declaration of Competing Interest}

The authors declare that they have no known competing financial interests or personal relationships that could have appeared to influence the work reported in this paper.

\section{Acknowledgements}

We greatly thank Pharmia Oy for donating the raw materials.

This research did not receive any specific grant from funding agencies in the public, commercial, or not-for-profit sectors.

\section{References}

Abdel-Hamid, S., Betz, G., 2012. A novel tool for the prediction of tablet sticking during high speed compaction. Pharm. Dev. Technol. 17, 747-754. https://doi.org/ 10.3109/10837450.2011.580761.

Ahlneck, C., Alderborn, G., 1989. Moisture adsorption and tabletting. I. Effect on volume reduction properties and tablet strength for some crystalline materials. Int. J. Pharm. 54, 131-141. https://doi.org/10.1016/0378-5173(89)90332-3.

Aizu, Y., Asakura, T., 1987. Principles and development of spatial filtering velocimetry. Appl. Phys. B Photophys. Laser Chem. 43, 209-224. https://doi.org/10.1007/ BF00692491.

Alderborn, G., Ahlneck, C., 1991. Moisture adsorption and tabletting. III. Effect on tablet strenght-post compaction storage time profiles. Int. J. Pharm. 73, 249-258. https:// doi.org/10.1016/0378-5173(91)90417-M.

Allen, L.V., Luner, P.E., 2009. Magnesium stearate. In: Rowe, R.C., Sheskey, P.J., Quinn, M.E. (Eds.), Handbook of Pharmaceutical Excipients, 6th Ed. Pharmaceutical Press, UK, pp. 404-407.

Armstrong, B., Brockbank, K., Clayton, J., 2014. Understand the effects of moisture on powder behavior. Chem. Eng. Prog. 110, 25.

Austin, P.C., Hux, J.E., 2002. A brief note on overlapping confidence intervals. J. Vasc. Surg. 36, 194-195. https://doi.org/10.1067/mva.2002.125015.

Baş, D., Boyacı, İ.H., 2007. Modeling and optimization I: Usability of response surface methodology. J. Food Eng. 78, 836-845. https://doi.org/10.1016/j. jfoodeng.2005.11.024.

Bell, L.N., 2007. Moisture Effects on Food's Chemical Stability, In: Barbosa-Cánovas, G. V., Fontana, A.J., Schmidt, S.J., Labuza, T.P. (Eds.), Water Activity in Foods: Fundamentals and Applications, 1st Ed., Blackwell Publishing Professional, USA, pp. 173-198.

Beuchat, L.R., Komitopoulou, E., Beckers, H., Betts, R.P., Bourdichon, F., Fanning, S., Joosten, H.M., ter Kuile, B.H., 2013. Low-water activity foods: increased concern as vehicles of foodborne pathogens. J. Food Prot. 76, 150-172. https://doi.org/ 10.4315/0362-028X.JFP-12-211.

Billings, S.W., Bronlund, J.E., Paterson, A.H.J., 2006. Effects of capillary condensation on the caking of bulk sucrose. J. Food Eng. 77, 887-895. https://doi.org/10.1016/j. jfoodeng.2005.08.031.

Bolhuis, G.K., Anthony Armstrong, N., 2006. Excipients for direct compaction-an update. Pharm. Dev. Technol. 11, 111-124. https://doi.org/10.1080/10837450500464255.

Bolhuis, G.K., Rexwinkel, E.G., Zuurman, K., 2009. Polyols as filler-binders for disintegrating tablets prepared by direct compaction. Drug Dev. Ind. Pharm. 35, 671-677. https://doi.org/10.1080/03639040802587799.

Bond, M., 2009. Xylitol. In: Rowe, R.C., Sheskey, P.J., Quinn, M.E. (Eds.), Handbook of Pharmaceutical Excipients, 6th ed. Pharmaceutical Press, UK, pp. 786-789.

Danjo, K., Kamiya, K., Otsuka, A., 1993. Effect of temperature on the sticking of low melting point materials. Chem. Pharm. Bull. 41, 1423-1427. https://doi.org/ 10.1248/cpb.41.1423.

Desbois, L., Tchoreloff, P., Mazel, V., 2019. Influence of the punch speed on the die wall/ powder kinematic friction during tableting. J. Pharm. Sci. 108, 3359-3365. https:// doi.org/10.1016/j.xphs.2019.05.007.

Garr, J.S.M., Rubinstein, M.H., 1990. Direct compression characteristics of xylitol. Int. J. Pharm. 64, 223-226. https://doi.org/10.1016/0378-5173(90)90272-6.

Juarez-Enriquez, E., Olivas, G.I., Zamudio-Flores, P., Ortega-Rivas, E., Perez-Vega, S., Sepulveda, D.R., 2017. Effect of water content on the flowability of hygroscopic powders. J. Food Eng. 205, 12-17. https://doi.org/10.1016/j. jfoodeng.2017.02.024.

[dataset] Juvonen, H., 2021. Supplementary data, Mendeley Data, V2, https://doi.org/ $10.17632 / \mathrm{k} 7 \mathrm{fp} 4986 \mathrm{pr} .2$.

Karehill, P.G., Glazer, M., Nyström, C., 1990. Studies on direct compression of tablets. XXIII. The importance of surface roughness for the compactability of some directly 
compressible materials with different bonding and volume reduction properties. Int. J. Pharm. 64, 35-43. https://doi.org/10.1016/0378-5173(90)90176-5.

Kato, H., Kimura, K., Izumi, S., Nakamichi, K., Danjo, K., Sunada, H., 2005. The effect of magnesium stearate particle size on tablet properties and tableting characteristics of granules prepared with standard formulation. J. Drug Delivery Sci. Technol. 15, 475-480. https://doi.org/10.1016/S1773-2247(05)50091-1.

Kelemen, A., 2015. Role of the particle size of sorbitol during the compression of common tablets and prediction of mini-tablet compression parameters. Chem. Eng. Res. Design 104, 814-818. https://doi.org/10.1016/j.cherd.2015.10.028.

Li, L.C., Peck, G.E., 1990. The effect of moisture content on the compression properties of maltodextrins. J. Pharm. Pharmacol. 42, 272-275. https://doi.org/10.1111/j.20427158.1990.tb05406.x.

Lipasek, R.A., Li, N., Schmidt, S.J., Taylor, L.S., Mauer, L.J., 2013. Effect of temperature on the deliquescence properties of food ingredients and blends. J. Agric. Food Chem. 61, 9241-9250. https://doi.org/10.1021/jf402585t.

Lipasek, R.A., Ortiz, J.C., Taylor, L.S., Mauer, L.J., 2012. Effects of anticaking agents and storage conditions on the moisture sorption, caking, and flowability of deliquescent ingredients. Food Res. Int. 45, 369-380. https://doi.org/10.1016/j. foodres.2011.10.037.

Lordi, N., Shiromani, P., 1983. Use of sorption isotherms to study the effect of moisture on the hardness of aged compacts. Drug Dev. Ind. Pharm. 9, 1399-1416. https://doi. org/10.3109/03639048309052384.

Mathlouthi, M., Rogé, B., 2003. Water vapour sorption isotherms and the caking of food powders. Food Chem. 82, 61-71. https://doi.org/10.1016/S0308-8146(02)00534-4.

Mauer, L.J., Taylor, L.S., 2010. Deliquescence of pharmaceutical systems. Pharm. Dev. Technol. 15, 582-594. https://doi.org/10.3109/10837450903397594.

Mizumoto, T., Masuda, Y., Yamamoto, T., Yonemochi, E., Terada, K., 2005. Formulation design of a novel fast-disintegrating tablet. Int. J. Pharm. 306, 83-90. https://doi. org/10.1016/j.ijpharm.2005.09.009.

Morris, L.E., Moore, J.C., Schwartz, J.B., 1996. Characterization and performance of a new direct compression excipient for chewable tablets: Xylitab. Drug Dev. Ind. Pharm. 22, 925-932. https://doi.org/10.3109/03639049609065922.

Ndindayino, F., Henrist, D., Kiekens, F., Vervaet, C., Remon, J.P., 1999. Characterization and evaluation of isomalt performance in direct compression. Int. J. Pharm. 189, 113-124. https://doi.org/10.1016/S0378-5173(99)00241-0.

Nezzal, A., Aerts, L., Verspaille, M., Henderickx, G., Redl, A., 2009. Polymorphism of sorbitol. J. Cryst. Growth 311, 3863-3870. https://doi.org/10.1016/j. jerysgro.2009.06.003.

Nikolakakis, I., Newton, J.M., Malamataris, S., 2002. Solid state 'adsorption' of fine antibiotic powders onto sorbitol: effects of particle size, state of sorbed water and surface free energy characteristics. Eur. J. Pharm. Sci. 17, 229-238. https://doi.org/ 10.1016/S0928-0987(02)00205-1.

Paul, S., Wang, K., Taylor, L.J., Murphy, B., Krzyzaniak, J., Dawson, N., Mullarney, M.P., Meenan, P., Sun, C.C., 2017. Dependence of punch sticking on compaction pressure - roles of particle deformability and tablet tensile strength. J. Pharm. Sci. 106, 2060-2067. https://doi.org/10.1016/j.xphs.2017.04.059.

Paul, S., Sun, C.C., 2018. Systematic evaluation of common lubricants for optimal use in tablet formulation. Eur. J. Pharm. Sci. 117, 118-127. https://doi.org/10.1016/j. ejps.2018.02.013.
Peleg, M., Mannheim, C.H., Passy, N., 1973. Flow properties of some food powders. J. Food Sci. 38, 959-964. https://doi.org/10.1111/j.1365-2621.1973.tb02124.x.

Rao, K.P., Chawla, G., Kaushal, A.M., Bansal, A.K., 2005. Impact of solid-state properties on lubrication efficacy of magnesium stearate. Pharm. Dev. Technol. 10, 423-437. https://doi.org/10.1081/PDT-54462.

Rojas, J., Hernández, S., 2014. Effect of the compaction platform on the densification parameters of tableting excipients with different deformation mechanisms. Chem. Pharm. Bull. 62, 281-287. https://doi.org/10.1248/cpb.c13-00884.

Salameh, A.K., Mauer, L.J., Taylor, L.S., 2006. Deliquescence lowering in food ingredient mixtures. J. Food Sci. 71, E10-E16. https://doi.org/10.1111/j.1365-2621.2006. tb12392.x.

Salameh, A.K., Taylor, L.S., 2005. Deliquescence in binary mixtures. Pharm. Res. 22, 318-324. https://doi.org/10.1007/s11095-005-1563-5.

Saniocki, I., Sakmann, A., Leopold, C., 2013. Evaluation of the suitability of various lubricants for direct compaction of sorbitol tablet formulations. J. Excipients Food Chem. 4, 169-182.

Saniocki, I., 2014. New Insights into Tablet Sticking: Characterization and Quantification of Sticking to Punch Surfaces during Tablet Manufacture by Direct Compaction. Doctoral dissertation. der Universität Hamburg.

Santomaso, A.C., Baggio, R., Zorzi, F., Salviulo, G., Realdon, N., Franceschinis, E., 2017. Sugars with different thickening power in high shear granulation. Powder Technol 317, 391-399. https://doi.org/10.1016/j.powtec.2017.05.017.

Schubert, H., 1984. Capillary forces - modeling and application in particulate technology. Powder Technol 37, 105-116. https://doi.org/10.1016/0032-5910(84) 80010-8.

Shur, J., 2009. Sorbitol. In: Rowe, R.C., Sheskey, P.J., Quinn, M.E. (Eds.), Handbook of Pharmaceutical Excipients, 6th Ed. Pharmaceutical Press, UK, pp. 679-682.

Stoklosa, A.M., Lipasek, R.A., Taylor, L.S., Mauer, L.J., 2012. Effects of storage conditions, formulation, and particle size on moisture sorption and flowability of powders: A study of deliquescent ingredient blends. Food Res. Int. 49, 783-791. https://doi.org/10.1016/j.foodres.2012.09.034.

Sun, C.C., 2015. Dependence of ejection force on tableting speed-A compaction simulation study. Powder Technol 279, 123-126. https://doi.org/10.1016/j. powtec.2015.04.004.

Thapa, P., Lee, A.R., Choi, D.H., Jeong, S.H., 2017. Effects of moisture content and compression pressure of various deforming granules on the physical properties of tablets. Powder Technol 310, 92-102. https://doi.org/10.1016/j. powtec.2017.01.021.

Uzondu, B., Leung, L.Y., Mao, C., Yang, C., 2018. A mechanistic study on tablet ejection force and its sensitivity to lubrication for pharmaceutical powders. Int. J. Pharm. 543, 234-244. https://doi.org/10.1016/j.ijpharm.2018.03.064.

Van Campen, L., Amidon, G.L., Zografi, G., 1983. Moisture Sorption kinetics for watersoluble substances I: theoretical considerations of heat transport control. J. Pharm. Sci. 72, 1381-1388. https://doi.org/10.1002/jps.2600721204.

Waimer, F., Krumme, M., Danz, P., Tenter, U., Schmidt, P.C., 1999. A novel method for the detection of sticking of tablets. Pharm. Dev. Technol. 4, 359-367. https://doi. org/10.1081/PDT-100101371.

Zografi, G., 1988. States of water associated with solids. Drug Dev. Ind. Pharm. 14, 1905-1926. https://doi.org/10.3109/03639048809151997. 